\title{
Case study of multiaxial criteria for rolling contact fatigue of bearing steels
}

\author{
Miroslav Vaculka ${ }^{1,2^{*}}$, Libor Nohál ${ }^{1,2}$, and Petr Vosynek ${ }^{1}$ \\ ${ }^{1}$ Faculty of Mechanical Engineering, Brno University of Technology, Technická 2896/2, 61669 Brno, Czech Republic \\ ${ }^{2}$ ZKL - Výzkum a vývoj, a.s., Jedovnická 2346/8, Líšeň, 62800 Brno, Czech Republic
}

\begin{abstract}
A rolling contact fatigue (RCF) differs from the classic fatigue in a stress-state. Nowadays, a prediction of the RCF is still not on the sufficient level. A lot of researchers tried to apply different multiaxial fatigue criteria (MFC) to the RCF, respectively they modified some or even proposed new one. Our paper focuses on assessment of bearing life estimation based on mentioned methods with experimental validation in laboratory. Comparison and summarization of different methods used in MFC life estimation is presented, with inclusion of fatigue material properties, hardness and probability. Mainly bearing steels are used for evaluation and region of high-cycle and giga-cycle fatigue.
\end{abstract}

\section{Introduction}

The rolling bearing is exposed to many types of failure during operation. These types are well described in the publication of Harris [1] who presents analytic methods for predict these failures. This study exclusively deals with the failure named Rolling Contact Fatigue (RCF) which leads to pitting (Fig. 1). It is not yet too wellknown to what extent the classic fatigue and the RCF are related. The difference is that the crack initiates on the surface of part within classic fatigue, whereas the crack initiates in subsurface layer in the RCF (macropitting) (Fig. 3). It is caused by cyclic contact loading which leads to a specific distribution of stress state and maximal shear stress beneath the surface (Fig. 2). Publications [2-5] describe an analogy between the classic and the rolling contact fatigue, on the basis of which Multiaxial Fatigue Criteria (MFC) can be used for the RCF, even though they were originally derived for the classic fatigue.

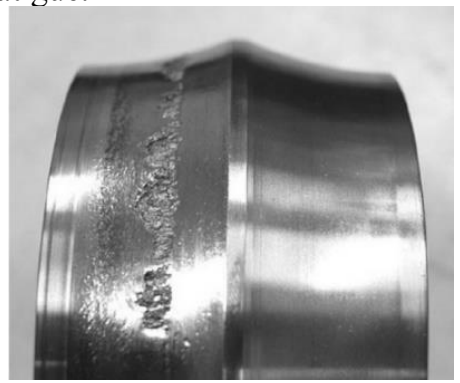

Fig. 1. Pitting on the inner ring surface of spherical roller bearing

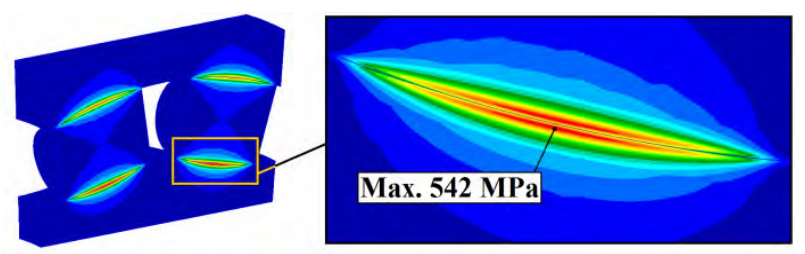

Fig. 2. Stress state in the contact area of roller and ring; Max Shear Stress in $[\mathrm{MPa}]$ is below the surface of raceway

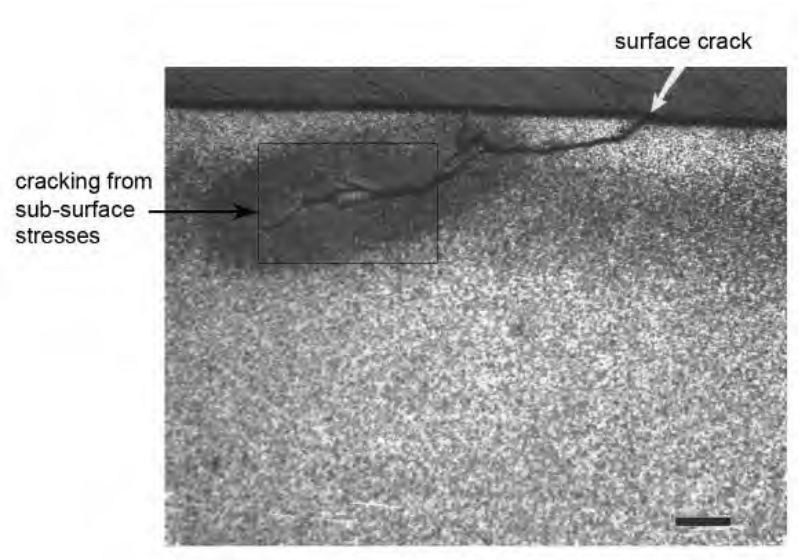

Fig. 3. Crack due to rolling contact fatigue [6]

Nowadays, it is well-known that due to stress raisers on the surface of bearing raceways, such as scratches, surfaces inclusions or other inhomogeneity, RCF cracks can initiate [7-9]. In this case, the failure is called micropitting. Micropitting is typical for modern high strength steels or bearing steels.

RCF can occur, for example, at the contact of a train wheel with rails or at gears. RCF at rolling bearings is specific because of the fact that the chrome bearing steel shows such resistance to fatigue that cracks occur in the gigacycle (ultra-high) region of fatigue.

Commonly used methodology for the assessment of service-life of rolling bearings is based on ISO 281 or more recently on the ISO 16281 standard. They have certain limitations which proposed methodology eliminates. The main benefit is the opportunity of using the Finite Element Method (FEM), which is how the stress state in rolling bearing is analyzed. Using MFC and this stress state is possible to evaluate the servicelife. There are some studies of appropriateness of MFC for this problem [10-12] but it has not been established yet which is the best. Therefore, a verification of MFC was proposed.

\footnotetext{
* Corresponding author: miroslav.vaculka@vutbr.cz
} 


\section{Multiaxial fatigue criteria}

Multiaxial fatigue criteria can be divided into several groups. This study primarily deals with the criteria for high-cycle fatigue. They divide into stress-based (or stress invariant based), based on critical plane approach and energy-based (or integral approach). According to the research of appropriateness, some of them are described below.

\subsection{Dang Van}

In literature, for simulations of life ended by RCF, we can frequently encounter the Dang Van criterion [16], proposed in form (1) $[10-11,13-15] . \tau_{\max }(t)$ is the instantaneous maximal shear stress, $\sigma_{h}(t)$ is the instantaneous hydrostatic stress, $\tau_{W}$ is the fatigue limit in reversal torque and $\sigma_{W}$ is the fatigue limit of fully reversed tension-compression or bending of rotation. Even though this criterion is used very often, it is inappropriate (too benevolent) $[14,17,18]$, because it does not consider the significant influence of negative hydrostatic stress.

$$
\tau_{\max }(t)+3\left(\frac{\tau_{W}}{\sigma_{W}}-\frac{1}{2}\right) \sigma_{h}(t) \leq \tau_{W}
$$

\subsection{Dang Van with locus by Desimone et. al}

As mentioned above, the Dang Van criterion does not provide appropriate results for life, so Desimone et. al [14] proposed an approach for its refinement. A failure locus for negative $\sigma_{h}$ in (1) modifies $\tau_{W}$ into a constant value (2).

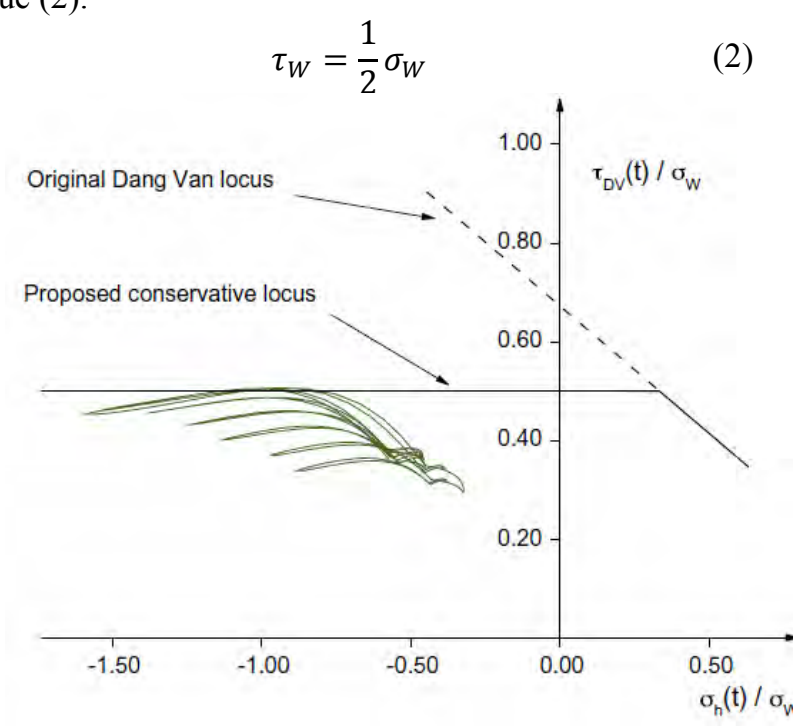

Fig. 4. Conservative locus for the Dang Van criterion applied to rolling/sliding contact [11]

This modification creates the failure locus illustrated in Fig. 4. Recent papers confirmed this work with experiments even for bearing steels $[11,19]$.

\subsection{Liu and Mahadevan}

The Liu and Mahadevan criterion [20, 21] provides a good match of life results with an experiment even for bearing steel. [11] provides a proof. The Liu and Mahadevan criterion is based on two characteristic planes - the critical plane, which is a plane of maximal amplitude of shear stress, and the plane of fatigue failure, where the macrocrack occurs. An angle difference between these two planes $\alpha$ can be calculated using (3) and (4).

$$
\begin{gathered}
s=\frac{\tau_{W}}{\sigma_{W}} \\
\cos (2 \alpha)=\frac{-2+\sqrt{4-4\left(\frac{1}{s^{2}}-3\right)\left(5-\frac{1}{s^{2}}-4 s^{2}\right)}}{2\left(5-\frac{1}{s^{2}}-4 s^{2}\right)}
\end{gathered}
$$

Using (5) and (6), the necessary parameters can be calculated and finally, using (7), the criterion is set up. $\sigma_{e q}$ is the amplitude of equivalent stress, $\sigma_{a, c}$ is the amplitude of normal stress, $\sigma_{m, c}$ is the mean value of normal stress, $\tau_{a, c}$ is the amplitude of maximal shear stress, and $\sigma_{a, c}^{H}$ is the amplitude of hydrostatic stress.

$$
\begin{gathered}
s \geq 1 \Rightarrow\left\{\begin{array}{c}
\beta=s \\
k=9\left(s^{2}-1\right) \\
\eta=1
\end{array}\right. \\
s<1 \Rightarrow\left\{\begin{array}{c}
\beta=\sqrt{(\cos 2 \alpha)^{2} s^{2}+(\sin 2 \alpha)^{2}} \\
k=0
\end{array}\right. \\
\eta=\frac{3}{4}+\frac{1}{4}\left(\frac{\sqrt{3}-\frac{1}{s}}{\sqrt{3}-1}\right) \\
=\frac{1}{\beta} \sqrt{\left[\sigma_{a, c}\left(1+\eta \frac{\sigma_{m, c}}{\sigma_{W}}\right)\right]^{2}+\left(\frac{\sigma_{W}}{\tau_{W}}\right)^{2}\left(\tau_{a, c}\right)^{2}+k\left(\sigma_{a, c}^{H}\right)^{2}}
\end{gathered}
$$

For the evaluation of a safety fatigue factor or even for the evaluation of the number of cycles up to a failure, a comparison with fatigue limit or with the S-N curve can be used (8).

$$
\sigma_{e q v} \leq \sigma_{W}
$$

\subsection{Crossland}

Crossland [22] and Sines are stated as simple criteria [23], but Crossland is the more successful one [24, 25]. For the Crossland criterion, $s_{m}(9)$, which is the centre of the smallest hypersphere circumscribing the load path in the deviatoric space (more in [26]), and stress deviator at the generic instant $s(t)$, must be evaluated. Now, it is possible to calculate (10) the amplitude of the square root of the second invariant of the deviatoric component of the stress tensor $\sqrt{J_{2, a}}$. Then, the final form can be stated as (11).

$$
\begin{gathered}
s_{m}=\min _{s^{\prime}} \max _{t} \sqrt{\frac{1}{2}\left(s(t)-s^{\prime}\right)\left(s(t)-s^{\prime}\right)} \\
\sqrt{J_{2, a}}=\max _{t} \sqrt{\frac{1}{2}\left(s(t)-s_{m}\right)\left(s(t)-s_{m}\right)} \\
\sqrt{J_{2, a}}+\left(\frac{3 \tau_{W}}{\sigma_{W}}-\sqrt{3}\right) \sigma_{h, \max } \leq \tau_{W}
\end{gathered}
$$




\subsection{Papadopoulos}

This criterion [27], based on mesoscopic scale, is proposed as the best agreement with out-of-phase bending and torsion experimental results for hard metals, where in (3) equation (12) applies for $s$. The criterion is estimated as (13).

$$
\begin{gathered}
0.557 \leq s \leq 0.8 \\
\sqrt{\left\langle T_{a}^{2}\right\rangle}+\left(\frac{3 \tau_{W}}{\sigma_{W}}-\sqrt{3}\right) \sigma_{h, \text { max }} \leq \tau_{W}
\end{gathered}
$$

In a simplified form, it is possible to say that $\sqrt{\left\langle T_{a}^{2}\right\rangle}$ is "the volumetric root mean square of the amplitude of the resolved shear stress on all possible planes" [10].

\subsection{Roessle-Fatemi}

One of the aims is the inclusion of the surface hardness to the calculation of rolling bearing durability. Poeppelman [28] used the Roessle-Fatemi criterion [29] for the fatigue evaluation of high hardness steels with appropriate results. In this study, this criterion is verified even for bearing steel.

The criterion is in fundamentals different from the others mentioned. It is based on the Coffin-Manson curve (strain-life approach). This means that it presumes plastic deformations. The criterion uses the Brinell hardness $H B$ to calculate the fatigue strength coefficient (14) and the fatigue ductility coefficient (15).

$$
\varepsilon_{f}^{\prime}=\frac{0.32(H B)^{2}-487(H B)+191000}{E}
$$

$\sigma_{f}^{\prime}$ is in $M P a$ and $E$ is the modulus of elasticity, also in $M P a$. Fatigue strength exponent $b$ was determined to be -0.09 and the fatigue ductility exponent $c$ to be 0.56 . The final criterion involves only the material hardness and the modulus of elasticity (16).

$$
\varepsilon_{a} \leq \frac{\sigma_{f}^{\prime}}{E}\left(2 N_{f}\right)^{-0.09}+\varepsilon_{f}^{\prime}\left(2 N_{f}\right)^{-0.56}
$$

[30] describes an inclusion of multiaxiality in this criterion. They use von-Mises, Tresca and maximum principal stress criteria.

\section{Proposed methodology of numerical solution}

The first part is the evaluation of stress state in the subsurface layer of raceway. This can be achieved using the Hertz theory at simple tasks. At more complex tasks, using ISO 16281 standard or using finite element method (FEM) is needed. The application of MFC follows. Criteria intended for high-cycle fatigue are proposed in form given by equation (17). $\sigma_{e q v}$ is the reduced stress characteristic for each criterion, and $\lambda$ is the limit value, e.g. fatigue limit. However, in this form they provide only the information of the fatigue safety factor. This study suggests using methodology proposed by Liu and Mahadevan [20] to extend the inequation (17) by the dependence on the number of cycles up to a failure (18), which allows a prediction of service-life.

$$
\sigma_{e q v} \leq \lambda
$$

$$
\sigma_{e q v}\left(N_{f}\right) \leq \lambda\left(N_{f}\right)
$$

For example, the Dang Van criterion (mentioned in (1)) can be converted into being the dependent on number of cycles up to a failure using (19) and (20) as follows.

$$
\begin{aligned}
& \sigma_{\mathrm{W}} \rightarrow \sigma_{\mathrm{W}}\left(N_{f}\right)=f_{-1} \\
& \tau_{\mathrm{W}} \rightarrow \tau_{\mathrm{W}}\left(N_{f}\right)=t_{-1}
\end{aligned}
$$

$t_{-1}$ replaces $\tau_{W} \cdot t_{-1}$ is a designation of shear stress in which the failure occurs for given number of cycles according to the fatigue test. Therefore, it is important to know such a part of S-N curve that describes the region of fatigue in which the failure of rolling bearings is expected.

A generalized form of the algorithm of numerical calculation of life may look as follows:

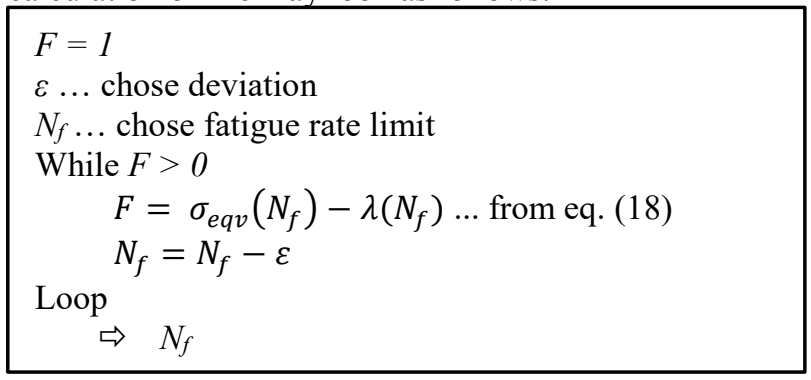

It means that at the beginning we define a variable $F>0$, then we choose $\varepsilon$ as a step that we use for finding $N_{f}$ as a trial and error method. If the inequation (18) does not apply, the algorithm is ended and the final value $N_{f}$ is found. The use of logarithm coordinates is preferable.

It is important to affect the difference between the number of revolutions, which is stated by basic durability $L_{10}$, and the number of cycles to which the bearing is exposed during this durability. A description of the calculation of the number of cycles is in [31]. It depends on the size and number of rolling elements. After several mathematical adjustments, it is possible to calculate it as (21). The parameters are described in Fig. $5, Z$ is the number of rolling elements (or balls).

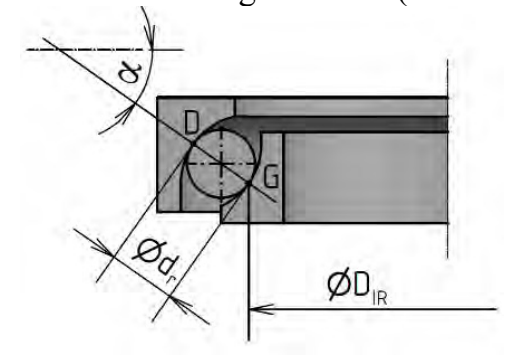

Fig. 5. The schema of bearing with important parameters for calculation. $\mathrm{D}, \mathrm{G}$ are contact points

$$
N_{f}=L_{10} \frac{Z}{1-\frac{D_{I R}}{2\left(D_{I R}-d_{r} \cos (\alpha)\right)}}
$$

\subsection{Application of the multiaxial fatigue criteria using material characteristics based on hardness}

This methodology is purely empirical, but it provides good results (see the verification below). S-N curve is 
determined using equations (14) and (15). The necessary coefficients describing the S-N curve can be calculated as (22). The final form of the S-N curve is presented in (23). Variable $N$ is number of cycles and it is in logarithm form.

$$
\begin{gathered}
A_{\sigma}=\sigma_{f}^{\prime} \cdot 2^{-0.09} \\
\sigma_{a}=A_{\sigma} \cdot\left(10^{N}\right)^{B_{\sigma}}
\end{gathered}
$$

Using these material characteristics, all criteria described in this study are applied with the same methodology.

\section{Verification}

Based on the described principle, some criteria where tested. For the verification, the experiment AXMAT II was chosen. FEM model of integral parts of the AXMAT test rig was created. The experiment and the numerical analysis are described in this section.

\subsection{Experiment}

The experimental RCF apparatus employed in this study is a flat washer-type RCF test-rig with acoustic emission and vibration monitoring systems. This special test-rig, shown in Fig. 6, was designed for life tests of thrust bearings (smaller size) and an evaluation of the rolling contact fatigue resistance of the material [32].It consists of a mechanical loading lever, an electrical motor, a specimen holder, a catch driver, a supporting frame and a monitoring system.

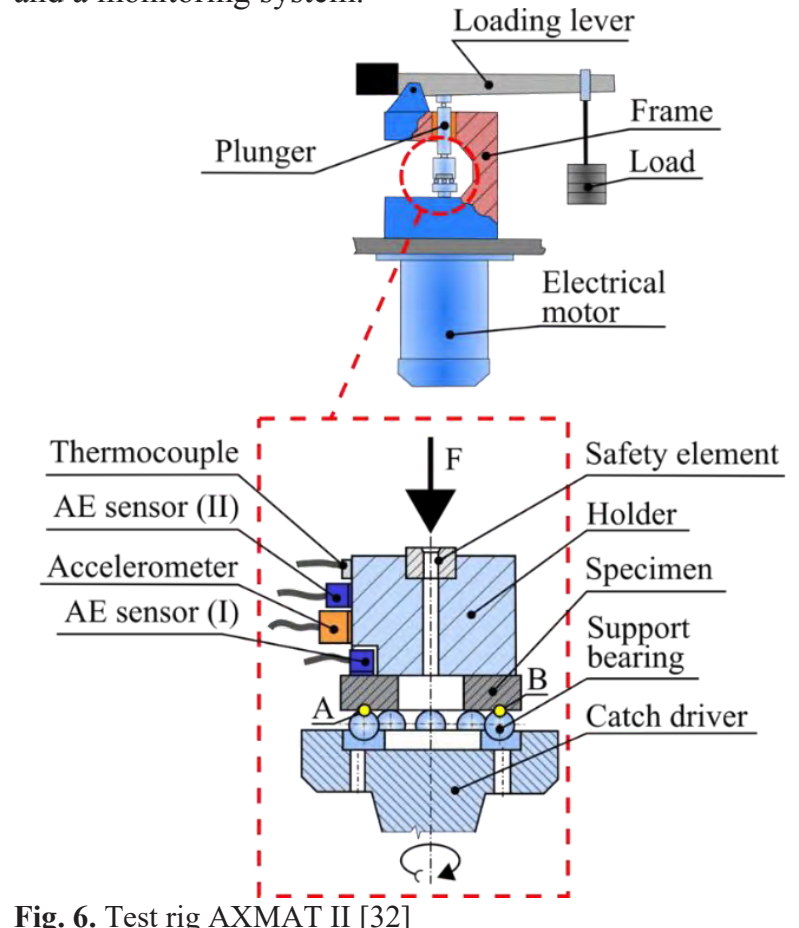

The speed of the electrical motor can be adjusted by a frequency converter to the required level. This allows standard RCF tests to be performed, including tests at low speeds. The upper ring of the test bearing is clamped in the holder and the lower ring is fastened in the catch driver. In the case of testing material specimens, the specimen was fastened in the holder in place of the upper bearing ring (the geometry of the specimen is shown in
Fig. 7). The holder is stationary, and the catch driver is driven by a shaft attached to an electrical motor. For a standard RCF test, the speed was set at $2150 \mathrm{~min}^{-1}$. The holder is equipped with a polyamide safety element to offload in case of specimen overheating. The Hertzian contact stress for rolling contact tests can be set using the combination of weights in the range from 2000 to $6000 \mathrm{MPa}$.

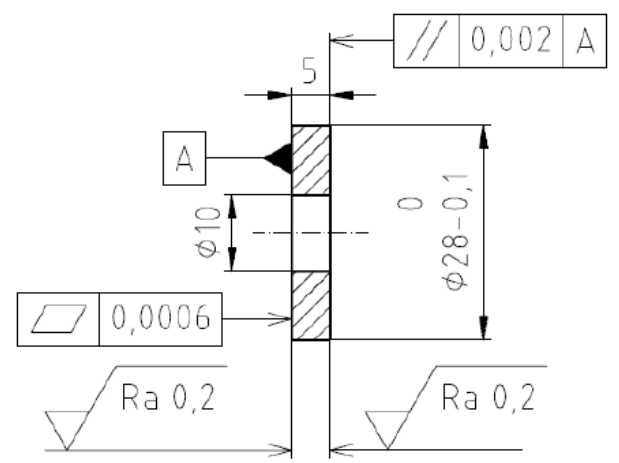

Fig. 7. Geometry of the specimen [32]

Table 1. Material characteristics (means) of applied material of

\begin{tabular}{|c|c|c|}
\hline Yield Stress & $\mathrm{R}_{\mathrm{p} 0,2}[\mathrm{MPa}]$ & 2021 \\
\hline Ultimate Strength & $\mathrm{R}_{\mathrm{m}}[\mathrm{MPa}]$ & 2040 \\
\hline Elongation & $\mathrm{A}[\%]$ & 0.3 \\
\hline Fatigue Limit & $\sigma_{f}[\mathrm{MPa}]$ & 945 \\
\hline Brinell Hardness & HB & \begin{tabular}{r|r}
$\mu$ & 647 \\
$\sigma$ & 10
\end{tabular} \\
\hline
\end{tabular}
hardened bearing steel 100Cr6MnSi6-4

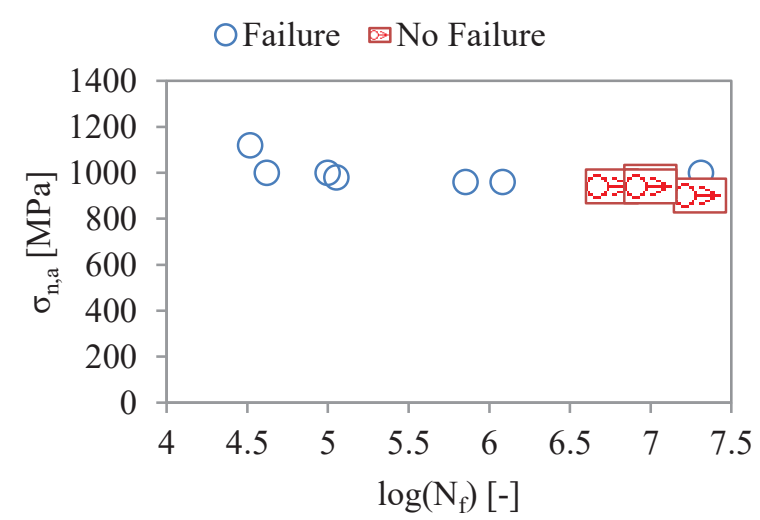

Fig. 8. Fatigue test of hardened bearing steel $100 \mathrm{Cr} 6 \mathrm{MnSi} 6-4$. $\mathrm{S}-\mathrm{N}$ curve is not determined due to brittleness of material

In this study, the specimen was loaded by force which should cause the contact stress of $5000 \mathrm{MPa}$ according to Hertzian calculation. This load causes plastic deformations, but the number of cycles up to failure is still in the high-cycle region. The reason of higher value of the load is that the experiment was very time consuming $(100-140 \mathrm{~h}$ per one specimen). Material characteristics of the tested material are in Table 1. This bearing steel was hardened and it is brittle (for brittle materials is in Eq. (3) $s \geq 1$ [11].). Therefore, the performance of fatigue tests was problematic, as shown in Fig. 8. Fatigue limit was determined (also in Table 1). 


\subsection{Numerical analysis}

The finite-element model of integral parts of the AXMAT test rig is created. These parts were housing washer, balls and the specimen. Thrust loading of this assembly was cyclic symmetric, therefore, only this symmetrical part of assembly was modelled (see Fig. 9). The material of the specimen was ideal elastic-plastic with bilinear behaviour. The elastic modulus $E=210 \mathrm{GPa}$ and the Poisson's ratio $v=0.3$ were used. For contact solution, augmented Lagrangian formulation was used.

Due to the plasticity, deformation shows a dent on the raceway surface of the specimen (Fig. 10). Therefore, contact pressure did not reach the stated value $5000 \mathrm{MPa}$, but $4179 \mathrm{MPa}$ (Fig. 11).

In the next part of the durability solution, the stress state of the specimen in the form of principal stresses was exported from the strain-stress analysis to the fatigue analysis. In $z$-axis only data under the contact point were used (Fig. 12). The stress results are shown in Fig. 13. Due to the plastic strain, peak-to-peak amplitude of maximal shear stress was not variable from a certain point beneath the surface.

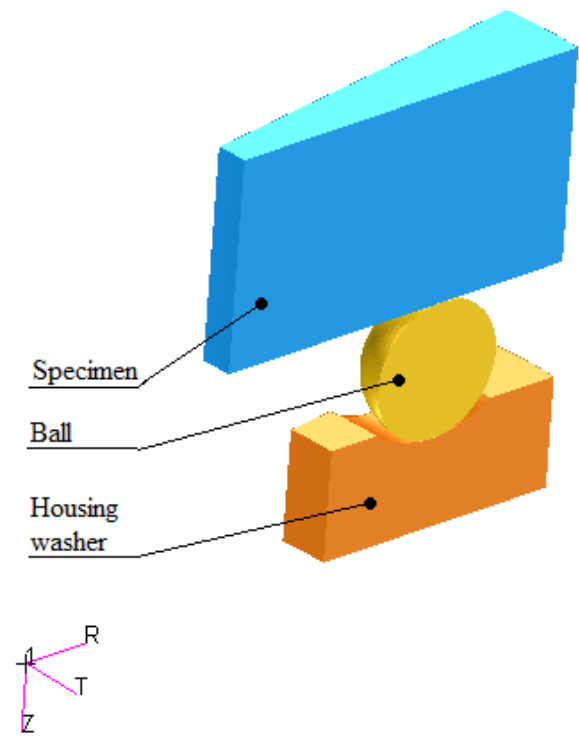

Fig. 9. Model of AXMAT specimen and support bearing used for FEM analysis

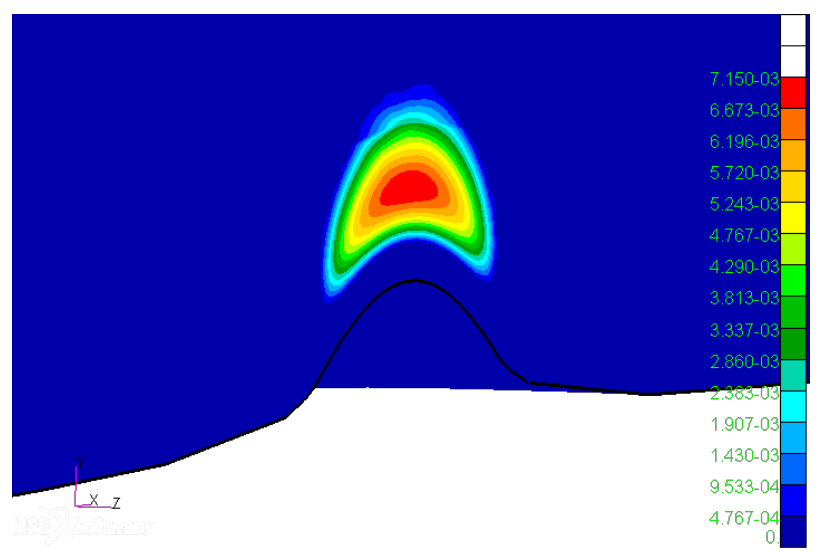

Fig. 10. Deforation of the area near the contact $(20 \mathrm{x}$ magnification), variable: plastic strain [-]

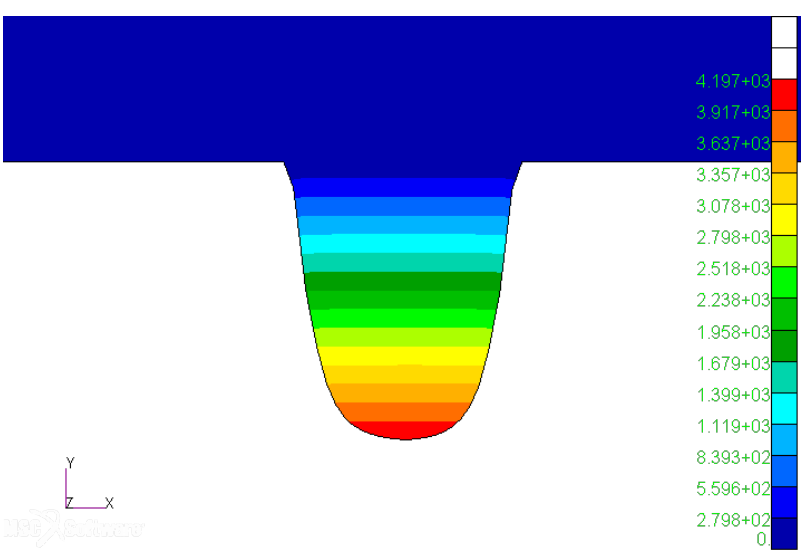

Fig. 11. Contact stress on specimen in $[\mathbf{M P a}]$. Due to occuring plastic strains, contact stress $5000 \mathbf{M P a}$ is not achieved

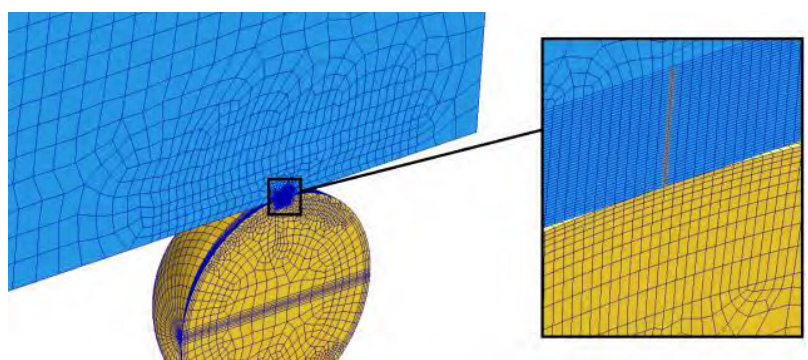

Fig. 12. Analysed nodes in subsurface layer

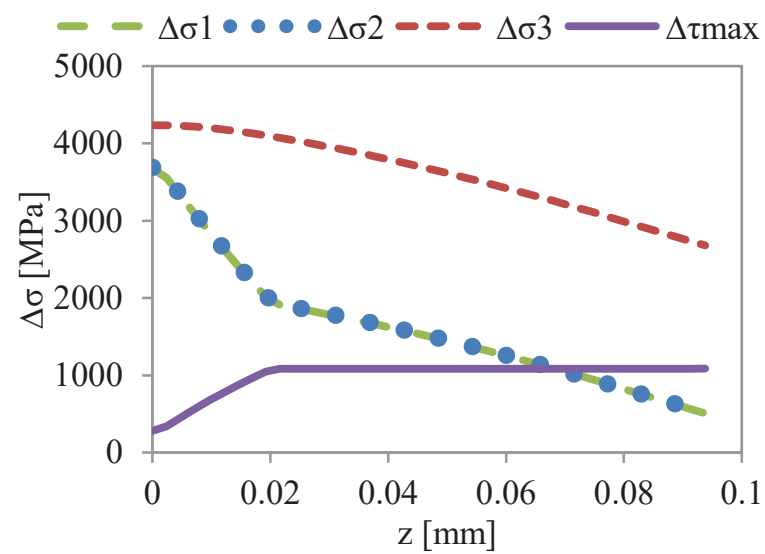

Fig. 13. Results of stress in subsurface layer due to elasticplastic material

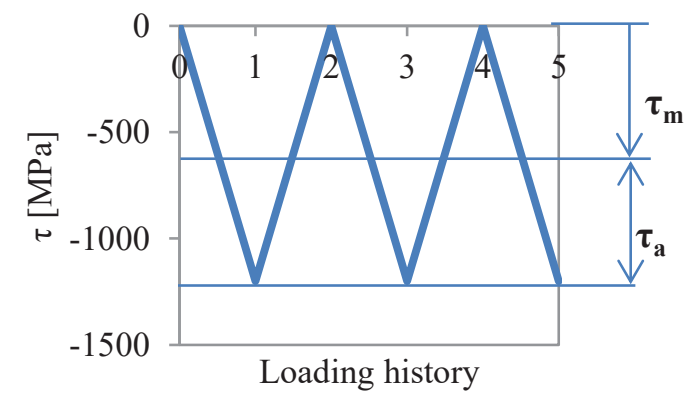

Fig. 14. An illustration of loading history of max shear stress and evaluation of mean value $\left(\tau_{\mathrm{m}}\right)$ and amplitude $\left(\tau_{\mathrm{a}}\right)$. Mean value is always negative and its absolute value is equal to amplitude

It was presumed that the thrust loading of test rig causes uniform distribution of load on all balls. Thus, the amplitude and mean stress are always the same and the fatigue estimation is not influenced by variable loading 
history. After each load of the analysed point, complete unload follows. Therefore, load history appears as shown in Fig. 14 and the amplitude and the mean stresses can be easily calculated. These data provided input for the criteria. The final results of the number of cycles up to failure was recalculated to a number of rotations using equation (21). Here, angle $\alpha$ was equal to $\pi / 2$, thus, the number of rotations were always equal to number of cycles divided by half of number of balls. Then, number of rotations is recalculated on time in hours.

From fatigue limit of the material of the specimen was established:

- No failure - criterion Dang Van, Crossland, Papadopoulos and Dang Van with modified locus

- Failure - criterion Liu Mahadevan

However, this study proposed an approach to life estimation in combination with setting the S-N curve from hardness and following calculation using MFC. The Gaussian distribution for hardness input is included. Therefore, results are given with their probability of failure. It is chosen probability $0.5,0.9,0.95$ and 0.99 . Results from this methodology are shown in Fig. 15.

\subsection{Discussion}

Measuring the S-N fatigue curve material characteristic of the $100 \mathrm{Cr} 6 \mathrm{MnSi6}-4$ bearing steel is problematic. Therefore, MFC cannot be used for life estimation, only for the failure prediction. Only the Liu and Mahadevan criterion predicts the failure in this case. MFC in combination with hardness properties can be effectively used for life estimation. From these results it is obvious that the Liu Mahadevan criterion is the most appropriate from all tested criteria.

Yet, there are several influences which were not included in the analysis. The most critical is that

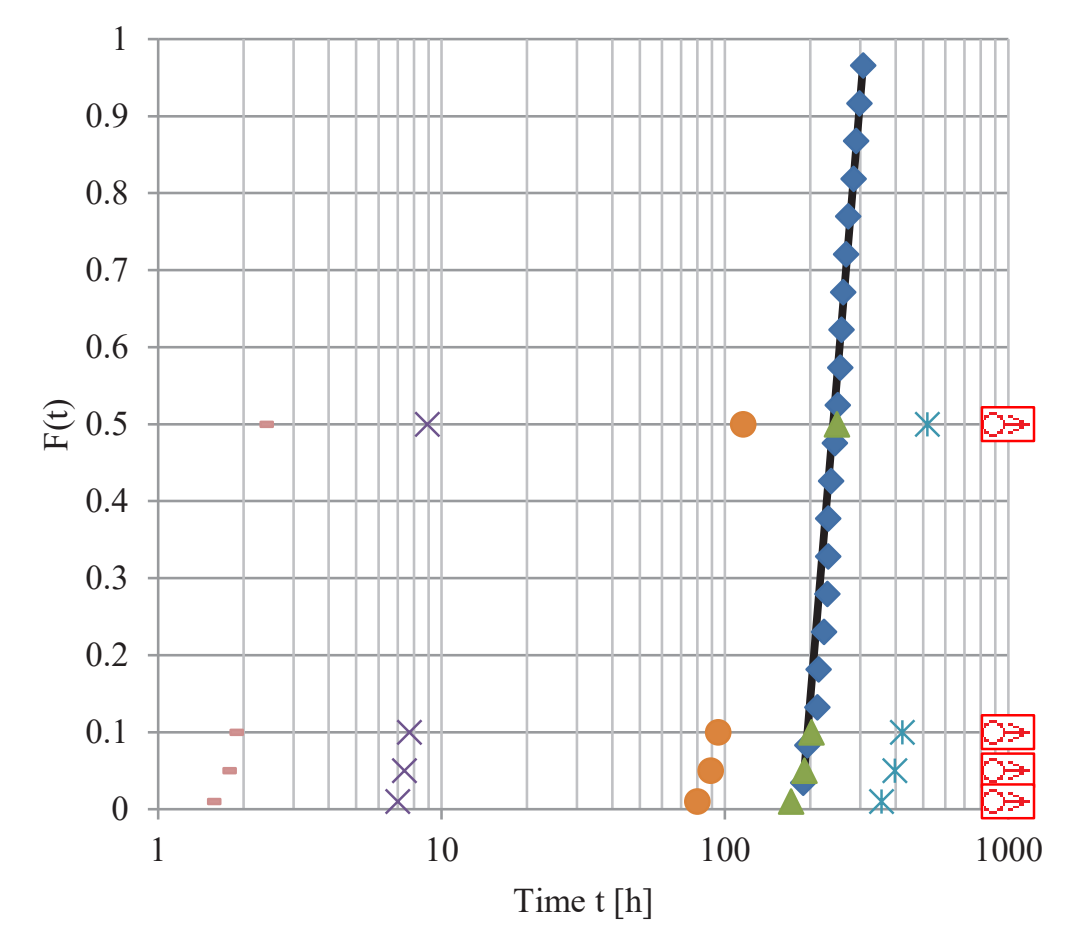

torsional fatigue tests were not performed. Also, the AXMAT experiment was not properly set up for time reasons $(100-140 \mathrm{~h}$ per specimen $)$. Contact pressure exceeded the appropriate limit and calculations could be influenced by plastic strains. A better way is set the loading with no following plastic deformation, but time can be significantly increased. Then, influences of macro- and micro-slippages and influences of roughness of surfaces still are not included in the analysis.

Due to the suggested verification of this study, more levels of loading were not tested. Also, more different types of material and different hardness of specimen surfaces should be tested in the future.

\section{Conclusion}

The methodology of the evaluation and the verification of the durability of rolling bearing has been proposed. Durability was evaluated as quantification of servicelife, which finishes together with the pitting occurrence. For the verification, the use of test-rig named AXMAT II was proposed. The $100 \mathrm{Cr} 6 \mathrm{MnSi}-4$ hardened bearing steel was tested. Weibull curve was drawn from these tests.

The procedure of durability calculation was described. Stress state or strain state respectively in area beneath the surface of raceways was input for calculation. This state together with material characteristics gained from fatigue tests input to multiaxial fatigue criteria. They were used in calculation and results were compared with the Weibull curve. The Liu and Mahadevan criterion seems to be the most appropriate for this application at this moment. But with the increasing number of tests, other criteria can be more appropriate for the rolling contact fatigue of rolling bearing.

$\checkmark$ Experiment - Results

Experiment - Weibull

- Liu Mahadevan using Hardness

$\times$ Crossland using Hardness

- Papadopoulos using Hardness

* Roessle Fatemi and VonMises using Hardness

- Roessle Fatemi and Tresca using Hardness

분 Both Dang Van and Dang Van with modified locus using hardness

Fig. 15. Comparison of experimental results of $100 \mathrm{Cr} 6 \mathrm{MnSi6}-4$ bearing steel and MFC (using hardness as input) results 
This work is an output of project NETME CENTRE PLUS (LO1202) created with financial support from the Ministry of Education, Youth and Sports under the "National Sustainability Programme I."

\section{References}

1. T. Harris, M. Kotzalas, Rolling bearing analysis, 5th ed., CRC/Taylor \& Francis, Boca Raton, FL (2007).

2. S. Way, Pitting due to rolling contact, J Appl Mech. (1935) A49-A58.

3. P. Rycerz, A. Olver, A. Kadiric, Propagation of surface initiated rolling contact fatigue cracks in bearing steel, International Journal of Fatigue. vol. 97 (2017) 29-38.

4. A. Olver, The Mechanism of Rolling Contact Fatigue: An Update, Proceedings of the Institution of Mechanical Engineers, Part J: Journal of Engineering Tribology. vol. 219 (2006) 313-330.

5. C. Chue, H. Chung, Pitting formation under rolling contact, Theoretical and Applied Fracture Mechanics. vol. 34 (2000) 1-9.

6. G. Dambaugh, Fatigue Considerations of High Strength Rolling Bearing Steels, Schaeffler Group USA, Inc. (2006) 33.

7. N. Soda, T. Yamamoto, Effect of Tangential Traction and Roughness on Crack Initiation/Propagation During Rolling Contact, A S L E Transactions. vol. 25 (2008) 198-206.

8. S. Borgese, An Electron Fractographic Study of Spalls Formed in Rolling Contact, Journal of Basic Engineering. vol. 89 (1967) 943-.

9. J. Martin, A. Eberhardt, Identification of Potential Failure Nuclei in Rolling Contact Fatigue, Journal of Basic Engineering. vol. 89 (1967) 932-.

10. M. Ciavarella, F. Monno, A comparison of multiaxial fatigue criteria as applied to rolling contact fatigue, Tribology International. vol. 43 (2010) 2139-2144.

11. S. Foletti, S. Beretta, M. Tarantino, Multiaxial fatigue criteria versus experiments for small crack under rolling contact fatigue, International Journal of Fatigue. vol. 58 (2014) 181-192.

12. E. Conrado, S. Foletti, C. Gorla, I. Papadopoulos, Use of multiaxial fatigue criteria and shakedown theorems in thermo-elastic rolling-sliding contact problems, Wear. vol. 270 (2011) 344-354.

13. B. Alfredsson, Applying multiaxial fatigue criteria to standing contact fatigue, International Journal of Fatigue. vol. 23 (2001) 533-548.

14. H. Desimone, A. Bernasconi, S. Beretta, On the application of Dang Van criterion to rolling contact fatigue, Wear. vol. 260 (2006) 567-572.

15. M. Ciavarella, F. Monno, G. Demelio, On the Dang Van fatigue limit in rolling contact fatigue, International Journal of Fatigue. vol. 28 (2006)

16. V. Dang, G. Cailletaud, J. Flavenot, A. Douaron, H. Liurade, Criterion for high cycle fatigue failure under multiaxial loading, ICBMFF2. (1986) 459-78.
17. A. Bernasconi, P. Davoli, M. Filippini, S. Foletti, An integrated approach to rolling contact sub-surface fatigue assessment of railway wheels, Wear. vol. 258 (2005) 973-980.

18. A. Ekberg, E. Kabo, H. Andersson, An engineering model for prediction of rolling contact fatigue of railway wheels, Fatigue html_ent glyph="@amp;" ascii="\&amp;"/ Fracture of Engineering Materials and Structures. vol. 25 (2002) 899-909.

19. L. Houpert, F. Chevalier, Rolling Bearing Stress Based Life-Part I: Calculation Model, Journal of Tribology. vol. 134 (2012) 021103-.

20. Y. Liu, S. Mahadevan, Multiaxial high-cycle fatigue criterion and life prediction for metals, International Journal of Fatigue. vol. 27 (2005) 790-800.

21. Y. Liu, B. Stratman, S. Mahadevan, Fatigue crack initiation life prediction of railroad wheels, International Journal of Fatigue. vol. 28 (2006) 747756.

22. B. Crossland, Effect of large hydrostatic pressure on the torsional fatigue strength of an alloy steel, Proc. Int. Conf. on Fatigue of Metals, Institution of Mechanical Engineers. (1956) 138-149.

23. G. Sines, Behavior of metals under complex static and alternating stresses, Metal Fatigue. (1959) 145469.

24. A. Banvillet, $A$ volumetric energy based high cycle multiaxial fatigue citerion, International Journal of Fatigue. vol. 25 (2003) 755-769.

25. A. Carpinteri, A. Spagnoli, Multiaxial high-cycle fatigue criterion for hard metals, International Journal of Fatigue. vol. 23 (2001) 135-145.

26. A. Bernasconi, Efficient algorithms for calculation of shear stress amplitude and amplitude of the second invariant of the stress deviator in fatigue criteria applications, International Journal of Fatigue. vol. 24 (2002) 649-657.

27. I. Papadopoulos, A comparative study of multiaxial high-cycle fatigue criteria for metals, International Journal of Fatigue. vol. 19 (1997) 219-235.

28. C. Poeppelman, Axial and Torsion Fatigue of High Hardness Steels, A Thesis (2011).

29. M. Roessle, Strain-controlled fatigue properties of steels and some simple approximations, International Journal of Fatigue. vol. 22 (n.d.) 495-511.

30. D. McClaflin, Torsional deformation and fatigue of hardened steel including mean stress and stress gradient effects, International Journal of Fatigue. vol. 26 (2004) 773-784.

31. M. Vaculka, Návrh metodiky výpočtu životnosti valivého ložiska, Diploma Thesis (2006).

32. L. Nohál, F. Hort, J. Dvořáček, P. Mazal, An experimental investigation of rolling contact fatigue of steels using acoustic emission method. Insight Non-Destructive Testing and Condition Monitoring vol. 55 (2013) 